\title{
PHENOLIC COMPOSITION AND ANTIOXIDANT PROPERTIES OF BRAZILIAN HONEYS
}

Fernanda B. Salgueiro, Aline F. Lira, Victor M. Rumjanek and Rosane N. Castro*

Departamento de Química, Instituto de Ciências Exatas, Universidade Federal Rural do Rio de Janeiro, 23890-000 Seropédica RJ, Brasil

Recebido em 25/10/2013; aceito em 11/02/2014; publicado na web em 08/05/2014

\begin{abstract}
The antioxidant activities and polyphenolic levels of "assa peixe," "cambara," and "morrão de candeia" Brazilian honeys were investigated. Phenolic extracts of 11 honeys were evaluated spectrophotometrically to determine their total phenolic and flavonoid contents, and their antioxidant activities were measured using DPPH, ABTS, and FRAP assays. High-performance liquid chromatography coupled with diode array detection was applied to determine the phenolic composition of the honey extracts. The presence of fourteen phenolic compounds was established (eleven phenolic acids and three flavonoids), as well as HMF and abscisic acid. Principal component analysis was applied to classify the honey samples according to their floral origins.
\end{abstract}

Keywords: Brazilian honeys; antioxidant; HPLC-DAD.

\section{INTRODUCTION}

Honey is a complex natural liquid that has been reported to contain around 200 substances. The composition of honey, especially of its secondary metabolites, is variable and primarily dependent on the floral source; however, some external factors also play a role, such as seasonal and environmental factors and the type of processing undertaken. Honey is a supersaturated solution with the main components being fructose $(38 \%)$ and glucose $(31 \%)$. A wide range of minor constituents is also present in honey, many of which are known to possess antioxidant properties. These include phenolic acids and flavonoids, certain enzymes (glucose oxidase-catalase), ascorbic acid, carotenoid-like substances, organic acids, Maillard reaction products, amino acids, and proteins. ${ }^{1,2}$

Phenolic acids and flavonoids are considered to be potential markers of the botanical origin of honey. Phenolic acids are further divided into two subclasses: substituted benzoic acids and substituted cinnamic acids. The classes of flavonoids present in honey include the flavonols, flavones, and flavanones. These compounds are important as they contribute to the color, taste, and aroma of honey; they also provide beneficial health effects to humans. ${ }^{3}$

Previous studies have shown that there is a strong correlation between the antioxidant activity of honey and its phenolic composition, especially the total phenolic content. ${ }^{3}$ Thus, characterization of phenolics and other components in honey that might have antioxidant properties is important to determine the functional properties of honey as a food that may promote health improvement. Characterization of the components of honey may also be an important tool for use in typification of honey. ${ }^{3,4}$

The objectives of this study were to quantify the total flavonoid and phenolic contents of eleven extracts of Brazilian unifloral honey types and to determine their antioxidant capacities. High-performance liquid chromatography with diode-array detection (HPLC-DAD) was used for the analysis of flavonoids and phenolic acids to identify and quantify the possible bioactive compounds responsible for the antioxidant activity of honey. This study highlights the applicability of HPLC data with multivariate statistical data sets for determining the floral origin of honey.

*e-mail: nora@ufrrj.br

\section{EXPERIMENTAL}

\section{Honey samples and reagents}

A total of 11 samples of three Brazilian honey types were used in this study: six samples of "cambara" (Gochnatia spp., Asteraceae) (C4; C5; C6; C7; C8; C9), three samples of "morrão de candeia" (Croton sp., Euphorbiaceae) (M2; M10; M11), and two samples of "assa peixe" (Vernonia spp., Asteraceae) (A1; A3). The samples were harvested in 2009 and 2011 and obtained from different geographical regions of Rio de Janeiro (Table 1) directly from beekeepers, who declared the botanical origins of the samples. The honeys were stored at $4{ }^{\circ} \mathrm{C}$ in the dark until analysis.

Table 1. Brazilian honeys analyzed in this work

\begin{tabular}{cccc}
\hline Samples & Honey type & Harvest date & Location \\
\hline A1 & "assa peixe" & September-2010 & Paracambi-RJ \\
M2 & "morrão de candeia" & June /July -2010 & Vassouras-RJ \\
A3 & "assa peixe" & August -2010 & Vassouras-SP \\
C4 & "cambara" & April-2010 & Seropédica-RJ \\
C5 & "cambara" & January-2010 & Seropédica-RJ \\
C6 & "cambara" & April-2010 & Seropédica-RJ \\
C7 & "cambara" & January-2010 & Seropédica-RJ \\
C8 & "cambara" & January-2010 & Seropédica-RJ \\
C9 & "cambara" & August -2010 & Seropédica-RJ \\
M10 & "morrão de candeia" & April - 2010 & Teresópolis-RJ \\
M11 & "morrão de candeia" & July - 2009 & Teresópolis-RJ \\
\hline
\end{tabular}

Methanol and HPLC grade acetic acid, aluminum chloride hexahydrate, potassium persulfate, and benzoic acid were purchased from VETEC (Rio de Janeiro, Brazil). The reagents TPTZ (2,4,6-tripyridyl-1,3,5-triazine), TROLOX (6-hydroxy-2,5,7,8-tetramethylchroman-2-carboxylic acid), DPPH (1,1-diphenyl-1-picrylhydrazyl), ABTS [2,2'-azino-bis-(3-ethylbenzothiazoline-6-sulfonic acid) diammonium salt], Folin-Denis reagent, gallic acid, protocatechuic acid, syringic acid, 4-hydroxybenzoic acid, ferulic acid, para-coumaric acid, para-methoxybenzoic acid, cinnamic acid, 
meta-methoxycinnamic acid; 2-cis,4-trans-abscisic acid (ABA), 5-hydroxymethylfurfural (HMF), naringenin, chrysin, galangin, and quercetin were supplied by Sigma-Aldrich Chemie (Steinheim, Germany). Unless otherwise specified, all chemicals used were of analytical grade.

\section{Extraction of phenolic compounds from honey samples}

The extraction of phenolic compounds from the eleven honey samples was performed as described previously ${ }^{5}$ with some modification. Honey samples $(100 \mathrm{~g})$ were mixed with $500 \mathrm{~mL}$ of acidified water (the $\mathrm{pH}$ was adjusted to 2 using concentrated $\mathrm{HCl}$ ). The fluid sample was then filtered through cotton wool to remove any solid particles. The filtrate was mixed with $150 \mathrm{~g}$ of Amberlite XAD-2 (Supelco, Bellefonte, PA, USA; pore size $9 \mathrm{~nm}$, particle size 0.3-1.2 $\mathrm{mm}$ ) and magnetically stirred for 10-15 $\mathrm{min}$ at room temperature. The mixture was then packed into a glass column $(45 \mathrm{~cm} \times 3.5 \mathrm{~cm})$, washed with $200 \mathrm{~mL}$ of acidified water ( $\mathrm{pH} 2$ with $\mathrm{HCl}$ ), and subsequently rinsed with $300 \mathrm{~mL}$ of neutral distilled water to remove all sugars and other polar compounds. The phenolic compounds were eluted from the sorbent using $500 \mathrm{~mL}$ of methanol. The extract obtained was concentrated under reduced pressure at $40{ }^{\circ} \mathrm{C}$ in a rotary evaporator. The residue was dissolved in $15 \mathrm{~mL}$ of distilled water and extracted five times with $10 \mathrm{~mL}$ of ethyl acetate. The extracts were combined and the solvent was evaporated. All measurements were performed in triplicate. The yields of extracts were expressed as a mean and ranged from $5.45 \mathrm{mg}$ to $64.75 \mathrm{mg}$ (Table 2).

\section{Determination of total phenolic content}

The total content of phenolic compounds was measured spectrophotometrically using a modified Folin-Denis method. ${ }^{6,7}$ The honey extract solutions $\left(2.0 \mathrm{mg} \mathrm{mL}^{-1}\right.$ in methanol) were homogenized and $0.5 \mathrm{~mL}$ of the extract solution was mixed with $2.5 \mathrm{~mL}$ of Folin-Denis reagent. After $5 \mathrm{~min}, 2 \mathrm{~mL}$ of a $14 \%$ sodium carbonate $\left(\mathrm{Na}_{2} \mathrm{CO}_{3}\right)$ solution was added. After $2 \mathrm{~h}$ of incubation at room temperature, the absorbance of the solution was measured against an ultrapure water blank at $760 \mathrm{~nm}$ (UV-Vis spectrophotometer, NI 2000UV Nova Instruments, São Paulo, Brazil). The total phenol content, expressed as milligrams of gallic acid equivalent per 100 milligrams of extract $\left(\mathrm{mg} \mathrm{GAE} 100 \mathrm{mg}^{-1}\right)$, was calculated using a calibration curve prepared with gallic acid standard solution $\left(0-0.022 \mathrm{mg} \mathrm{mL}^{-1} ; \mathrm{Y}=4.75098 \mathrm{X}\right.$ $+23.73359 ; \mathrm{R}=0.99313$ ), which was analyzed in the same way as the extracts. All measurements were performed in triplicate.

\section{Determination of total flavonoid content}

The total flavonoids were evaluated using the method described by Sant'ana et al. ${ }^{7}$ Briefly, $2 \mathrm{~mL}$ of a $2 \%$ aluminum trichloride methanolic solution was added to the same volume of honey extract solution ( $2.0 \mathrm{mg} \mathrm{mL}^{-1}$ in methanol). After $30 \mathrm{~min}$ of incubation, the absorbance values were measured at $415 \mathrm{~nm}$ against a methanol blank. The total flavonoid content, expressed as milligrams of quercetin equivalent per 100 milligrams of extract (mg QE $100 \mathrm{mg}^{-1}$ ), was calculated using a calibration curve prepared with quercetin $\left(0-0.020 \mathrm{mg} \mathrm{mL}^{-1} ; \mathrm{Y}=6.95836 \mathrm{X}+27.0114 ; \mathrm{R}=0.99296\right)$ that was analyzed in the same manner as the extracts. All measurements were performed in triplicate.

\section{Determination of antioxidant activity (DPPH assay)}

The antioxidant activity of the samples was measured using a DPPH assay using the method of Zang and Hamauzu ${ }^{8}$ with some modification. In the presence of an antioxidant agent, the purple color of DPPH decays and the change in absorbance is read spectrophotometrically at $517 \mathrm{~nm}$. Seventy-one microliters of honey extract solution $\left(5-100 \mu \mathrm{g} \mathrm{mL}^{-1}\right)$ or the phenolic standard (5-500 $\mu \mathrm{M}$ ) were mixed with $29 \mu \mathrm{L}$ of $0.3 \mathrm{mM}$ DPPH in methanol. ${ }^{9}$ A mixture of methanol $(29 \mu \mathrm{L})$ with honey extract $(71 \mu \mathrm{L})$ or a standard solution $(71 \mu \mathrm{L})$ was used as a blank, and a mixture of a DPPH solution $(29 \mu \mathrm{L})$ with methanol $(71 \mu \mathrm{L})$ was used as a negative control. After $30 \mathrm{~min}$ of incubation at room temperature in a dark place, the absorbance values were measured at $517 \mathrm{~nm}$ using an ELISA 680 microplate reader (Bio-Rad, Brazil). The antioxidant activity was calculated as the percentage of DPPH discoloration using equation (1), where \% AA = inhibition percentage, $\mathrm{AB}=$ average absorption of a blank sample at the end of the reaction, $\mathrm{AA}=$ average absorption of a tested honey or phenolic extract at the end of the reaction, and $\mathrm{AC}=$ average absorption of a negative control at the end of the reaction,

$$
\% \mathrm{AA}=100-[(\mathrm{AA}-\mathrm{AB}] / \mathrm{AC}) \times 100
$$

The half-maximum effective concentration $\left(\mathrm{EC}_{50}\right)$ was calculated by interpolation from the graph using \%AA values against honey, extract, or phenolic standard concentration. All measurements were performed in triplicate.

\section{Determination of antioxidant activity (ABTS assay)}

Determination of antioxidant activity was performed using the method described by Sant' ana et al. ${ }^{7}$ The $\mathrm{ABTS}^{+}$radical was produced by reacting $5 \mathrm{~mL}$ of ABTS stock solution $(7 \mathrm{mM})$ with $440 \mu \mathrm{L}$ of $140 \mathrm{mM}$ potassium persulfate solution. After $16 \mathrm{~h}$ of incubation at room temperature in a dark place, $2 \mathrm{~mL}$ of this solution was diluted with absolute ethanol to obtain an absorbance of $0.700 \pm 0.005$ at $734 \mathrm{~nm}$. Fifty microliters of the honey extract solution $\left(2.0 \mathrm{mg} \mathrm{mL}^{-1}\right)$ were mixed with $5 \mathrm{~mL}$ of $\mathrm{ABTS}^{+}$solution. After $6 \mathrm{~min}$, absorbance readings were taken at $734 \mathrm{~nm}$ using absolute ethanol as a blank. A calibration curve was prepared with Trolox solution (0.000-2.400 $\left.\mathrm{mmol} \mathrm{L}^{-1} ; \mathrm{Y}=-26.37778 \mathrm{X}+0.65164 ; \mathrm{R}=-0.9997\right)$. The data were expressed as millimoles of Trolox equivalent per 100 milligrams of extract (mmol TE $\left.100 \mathrm{mg}^{-1}\right)$. All measurements were performed in triplicate.

\section{Determination of antioxidant activity (FRAP assay)}

Antioxidant activity was evaluated using the method described by Sant'ana et al. ${ }^{7}$ The ferric reducing antioxidant assay (FRAP) was conducted to assess the ability of samples to reduce the ferric 2,4,6-tripyridyl-s-triazine complex ( $\mathrm{Fe}^{3+}$-TPTZ complex) to its blue ferrous form complex ( $\mathrm{Fe}^{2+}$-TPTZ complex). The FRAP reagent was prepared daily by mixing $10 \mathrm{~mL}$ of an aqueous $10 \mathrm{mM}$ TPTZ (2,4,6-tripyridyl-s-triazine) solution in $40 \mathrm{mM} \mathrm{HCl}, 10 \mathrm{~mL}$ of a 20 $\mathrm{mM}$ ferric chloride solution, and $100 \mathrm{~mL}$ of a $0.3 \mathrm{M}$ acetate buffer (pH 3.6). The reaction was then performed by mixing $0.5 \mathrm{~mL}$ of the honey phenolic extract solution $\left(2.0 \mathrm{mg} \mathrm{mL}^{-1}\right)$ with $4.5 \mathrm{~mL}$ of the FRAP reagent. After $10 \mathrm{~min}$ of incubation at $37^{\circ} \mathrm{C}$, the absorbance was measured at $593 \mathrm{~nm}$ using $0.5 \mathrm{~mL}$ of methanol in $4.5 \mathrm{~mL}$ of the FRAP reagent as a blank. Quantitative analyses were performed using the external standard method using ferrous sulfate $(100-1000 \mu \mathrm{M} ; \mathrm{Y}$ $=0.0018 \mathrm{X}+0.00107 ; \mathrm{R}=0.99961)$ as the standard and correlating the absorbance with the concentration. The results were calculated and expressed as millimoles of $\mathrm{Fe}^{2+}$ equivalent per 100 milligrams of extract (mmol Fe(II) $100 \mathrm{mg}^{-1}$ ). All measurements were performed in triplicate. 


\section{HPLC analysis}

Analyses of the honey extracts were performed on an HPLC-DAD Shimadzu Prominence system fitted with a LC-20AT pump module, a SPD- M20A diode array detector, a CBM-20A control center, a Rheodyne ${ }^{\circledR}$ manual injector, and a CTO-20A oven (Shimadzu, Japan). Acquisition and data analysis were performed using LCSolution software (Shimadzu, Japan). Separation was obtained with a Betasil C18 column $(250 \mathrm{~mm} \times 4.5 \mathrm{~mm}, 5 \mu \mathrm{m}$; Thermo Fisher Scientific, Runcorn, UK), using $1 \%$ acetic acid in water (solvent A) and $10 \%$ acetonitrile in methanol (solvent B) as the mobile phase at a constant flow rate of $1.0 \mathrm{~mL} \mathrm{~min}{ }^{-1}$. The gradient $(\mathrm{v} / \mathrm{v})$ began with $35 \%$ of solvent $\mathrm{B}$, rising to $70 \%$ at $20 \mathrm{~min}, 85 \%$ at $25 \mathrm{~min}$, and $100 \%$ at $30 \mathrm{~min}$, and remaining at this concentration for another 5 min. The injection volume was $20 \mu \mathrm{L}$ and the chromatograms were recorded at $280 \mathrm{~nm}$ and $320 \mathrm{~nm}$. The identification of phenolic acids and flavonoids present in the extracts was based on the comparison of retention times and UV spectral characteristics with those of authentic standards, and quantification was performed using external calibration data for the same compounds. The honey extracts were carefully dissolved in methanol (HPLC grade), filtered through a membrane filter, and injected. Quantitative results are expressed as $\mathrm{mg}$ of compound per $100 \mathrm{~g}$ of honey.

\section{Statistical analysis}

Multivariate analysis was performed using the software The Unscrambler X 10.1. The data on flavonoids and phenolic compounds were analyzed using principal component analysis (PCA) to discover natural groupings that could be used for honey typification. Evaluation of the correlation among the variables and construction of the correlation matrix were performed with the software BioEstat 5.0 and Microsoft Office Excel 2010. The results were significant at $\mathrm{p}<0.05$ unless specified otherwise.

\section{RESULTS AND DISCUSSION}

Eleven honey extracts of different floral types were evaluated to determine their antioxidant properties and to find possible relationships among total phenolic content, flavonoid content, antioxidant activity, and floral and geographical origins.

\section{Total Phenolic Content (TP) and Flavonoid Content (TF)}

The total content of polyphenolics from different Brazilian honey extracts was investigated using the modified Folin-Denis assay, which is sensitive to phenol and polyphenol entities and other electron-donating antioxidants such as ascorbic acid. The total

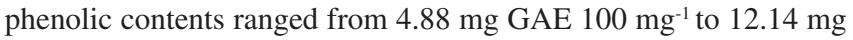
GAE $100 \mathrm{mg}^{-1}$ for the extract using a standard curve for gallic acid $(\mathrm{R}=0.99985)$. One of the "assa peixe" samples (A1) had the highest total phenolic content (12.14 mg GAE $\left.100 \mathrm{~g}^{-1}\right)$. The mean values and standard deviations are shown in Table 2.

The TP content showed significant differences between the groups. The "cambara" samples had the lowest levels, and the highest levels were measured in "assa peixe" extracts. Variations in total polyphenol content may be caused by different honey sources and storage conditions. The total flavonoid content (TF) was determined using the aluminum chloride method, which is specific to flavones and flavonols. The TF content of extracts was determined using the standard curve generated for quercetin $(\mathrm{R}=0.9918)$. The results are shown in Table 2, and ranged from $0.36 \mathrm{mg}$ QE $100 \mathrm{mg}^{-1}$ to 1.79 $\mathrm{mg}$ QE $100 \mathrm{mg}^{-1}$. The highest levels were observed for "assa peixe" samples. The levels of phenolic acids are higher than those of flavonoids in these samples. This trend was expected, and was previously observed by Sant'Anna et al. ${ }^{10}$ and Lianda et al. ${ }^{11}$ in Brazilian honeys.

The results of TF contents obtained for honey extracts were lower than the values previously reported for other Brazilian honeys, ${ }^{11}$ which ranged from 12.72 to $76.65 \mathrm{mg} \mathrm{GAE} 100 \mathrm{~g}^{-1}$ and 0.16 to $5.34 \mathrm{mg} \mathrm{QE} 100 \mathrm{~g}^{-1}$. The values of TP content obtained by Silva et al. ${ }^{12}$ for Brazilian melipona honey extracts were also higher than those found in this study. The variation in the TP and TF contents among the analyzed honey samples may be caused by variation in the floral sources, because different plants contain different phenolic compounds and show variation in their phenolic contents. ${ }^{4,13}$

The results of this study agree with those of previous work, which reported a correlation between total phenolic content and antioxidant activity (samples displaying lower phenolic contents also showed lower antioxidant activity).,

\section{Total Antioxidant Activity (TAA)}

Antioxidant activity is the ability of honey to slow oxidative reactions within food systems and the human body..$^{13}$ The results for antioxidant activity using the DPPH, ABTS, and FRAP methods for different honey extracts are summarized in Table 2. Previous studies have reported that the DPPH, ABTS, and FRAP assays are valid methods to determine the antioxidant properties of food, $, 11,14$ and the same procedures are also used to evaluate the antioxidant power of honey extracts.

The TAA (EC ${ }_{50}$, FRAP, and ABTS) values were 278.61-1601.8 $\mu \mathrm{g} \mathrm{mL} \mathrm{mL}^{-1}, 23.88-116.47 \mathrm{mmol} \mathrm{Fe}(\mathrm{II}) 100 \mathrm{~g}^{-1}$, and 30.88-137.79 $\mathrm{mmol}$

Table 2. Total phenolic (TP), flavonoid (TF) contents, antioxidant activities and yields of the honey extracts ${ }^{\mathrm{a}}$

\begin{tabular}{|c|c|c|c|c|c|c|}
\hline Samples $^{\mathrm{b}}$ & $\mathrm{TP}$ & $\mathrm{TF}$ & FRAP & ABTS & $\mathrm{EC}_{50}$ & Yields of extracts (mg) \\
\hline A1 & $12.14 \pm 0.01$ & $1.79 \pm 0.00$ & $116.47 \pm 0.00$ & $92.07 \pm 0.00$ & $521.79 \pm 0.02$ & $8.00 \pm 3.96$ \\
\hline M2 & $10.72 \pm 0.00$ & $1.54 \pm 0.00$ & $113.69 \pm 0.00$ & $67.70 \pm 0.00$ & $278.61 \pm 0.01$ & $5.45 \pm 6.43$ \\
\hline A3 & $7.15 \pm 0.01$ & $0.79 \pm 0.00$ & $34.06 \pm 0.00$ & $33.55 \pm 0.00$ & $448.96 \pm 0.01$ & $16.95 \pm 6.58$ \\
\hline $\mathrm{C} 4$ & $6.40 \pm 0.01$ & $0.48 \pm 0.00$ & $23.88 \pm 0.00$ & $35.05 \pm 0.00$ & $890.07 \pm 0.00$ & $61.75 \pm 8.84$ \\
\hline $\mathrm{C} 5$ & $6.50 \pm 0.01$ & $0.44 \pm 0.00$ & $59.06 \pm 0.00$ & $109.07 \pm 0.00$ & $302.79 \pm 0.01$ & $49.55 \pm 5.87$ \\
\hline C6 & $7.38 \pm 0.02$ & $0.53 \pm 0.00$ & $67.39 \pm 0.00$ & $137.79 \pm 0.00$ & $455.74 \pm 0.01$ & $46.35 \pm 20.15$ \\
\hline $\mathrm{C} 7$ & $7.12 \pm 0.00$ & $0.36 \pm 0.00$ & $44.25 \pm 0.00$ & $30.88 \pm 0.00$ & $1601.8 \pm 0.01$ & $24.55 \pm 11.38$ \\
\hline $\mathrm{C} 8$ & $5.13 \pm 0.00$ & $0.37 \pm 0.00$ & $48.48 \pm 0.00$ & $94.70 \pm 0.00$ & $624.88 \pm 0.02$ & $64.75 \pm 33.02$ \\
\hline C9 & $4.88 \pm 0.01$ & $1.64 \pm 0.00$ & $44.25 \pm 0.002$ & $98.23 \pm 0.00$ & $440.47 \pm 0.01$ & $41.10 \pm 30.83$ \\
\hline M10 & $11.05 \pm 0.00$ & $1.64 \pm 0.00$ & $92.86 \pm 0.00$ & $69.85 \pm 0.01$ & $638.02 \pm 0.01$ & $8.85 \pm 2.90$ \\
\hline M11 & $11.00 \pm 0.01$ & $0.56 \pm 0.00$ & $73.42 \pm 0.00$ & $131.41 \pm 0.00$ & $348.53 \pm 0.01$ & $34.00 \pm 8.77$ \\
\hline
\end{tabular}

${ }^{2}$ All data expressed on extract weight basis as means $\pm \mathrm{SD}(\mathrm{n}=3)$. ${ }^{\mathrm{b}} \mathrm{M}=$ "morrão de candeia" honeys; $\mathrm{A}=$ "assa peixe" honeys; $\mathrm{C}=$ "cambara" honeys. The

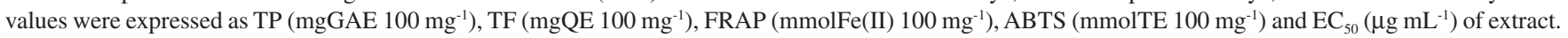


TE $100 \mathrm{~g}^{-1}$, respectively. The "morrão de candeia" samples showed the highest values for antioxidant activity, and one of the "cambara" samples (C7) was the least reactive species for trapping of free radicals, compared to "assa peixe" and "morrão de candeia" honeys. The values obtained in this study are lower than those reported by Lianda et al. ${ }^{11}$ for FRAP, ABTS, and $\mathrm{EC}_{50}$ assays (78.51-438.69 mmol Fe(II) $100 \mathrm{~g}^{-1}, 46.53-383.49 \mathrm{mmol}$ TE $100 \mathrm{~g}^{-1}$, and 5.48-51.45 $\mu \mathrm{g} \mathrm{mL}^{-1}$, respectively) for Brazilian extracts and by Estevinho et al. ${ }^{15}$ for $\mathrm{EC}_{50}$.

One of the "morrão de candeia" samples (M2), showed the highest radical scavenging activity $\left(\mathrm{EC}_{50}=278.61 \mu \mathrm{g} \mathrm{mL}-1\right)$ and one of

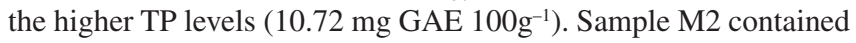
4-hydroxybenzoic, syringic, and gallic acids $\left(0.010 \mathrm{mg} 100 \mathrm{~g}^{-1}, 0.055\right.$ $\mathrm{mg} 100 \mathrm{~g}^{-1}$, and $0.001 \mathrm{mg} 100 \mathrm{~g}^{-1}$ of honey, respectively). Honey extract C7, with one of the lower antioxidant capacities $\left(\mathrm{EC}_{50}=890.07\right.$ $\mathrm{mg} \mathrm{mL}^{-1}$ ), contained two compounds with low antioxidant activity (Table 4): naringenin $\left(\mathrm{EC}_{50}>5000 \mu \mathrm{g} \mathrm{mL}^{-1}\right)$ and meta-coumaric acid $\left(\mathrm{EC}_{50}>15000 \mu \mathrm{g} \mathrm{mL}-1\right)$.

\section{Identification of phenolic constituents using HPLC-PDA}

The HPLC analysis of Brazilian honey extract samples indicated the presence of eleven phenolic acids: gallic acid, protocatechuic acid, 4-hydroxybenzoic acid, syringic acid, ferrulic acid, para-coumaric acid, meta-coumaric acid, benzoic acid, para-methoxybenzoic acid, cinnamic acid, and meta-methoxycinnamic acid; three flavonoids: naringenin, chrysin, and galangin, and 5-hydroxymethylfurfural (HMF) and abscisic acid (ABA). Most of these compounds were found in all three honey types, but in different amounts. Identification and quantification of phenolics was performed by comparison of their retention times and UV spectra with those of standard solutions of pure reference substances. Table 3 shows the values for flavonoids, phenolic acids, ABA, and HMF levels in honey extracts.

Phenolic acids represent the majority of the total identified phenolic compounds present in each analyzed honey sample, as well as abscisic acid and HMF. The content of abscisic acid varies from $0.016 \mathrm{mg} 100 \mathrm{~g}^{-1}$ to $0.394 \mathrm{mg} 100 \mathrm{~g}^{-1}$ of honey. This amount is similar to those reported in literature for Portuguese ${ }^{15}$ and Polish ${ }^{16}$ honeys. Gallic acid was observed in almost all honey samples, but

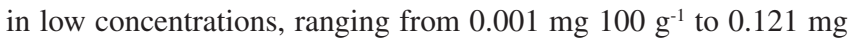

$100 \mathrm{~g}^{-1}$ of honey.

In addition to abscisic and gallic acids, significant amounts of protocatechuic, ferulic, para-coumaric, para-methoxybenzoic, and cinnamic acids were also determined to be present in "assa peixe" honeys, and 4-hydroxybenzoic, syringic, para-coumaric, meta-coumaric, and benzoic acids were found in "morrão de candeia" samples.

In comparison with "assa peixe" and "morrão de candeia" honeys, differences in the profiles of phenolic compounds were observed in "cambara" honeys. HPLC analysis indicated the presence of nine phenolic compounds. For phenolic acids, the presence of six acids (gallic, syringic, meta-coumaric, benzoic, cinnamic, and meta-methoxycinnamic) were determined.

For "cambara" samples, relatively large values of meta-coumaric acid, meta-methoxycinnamic acid, and naringenin were observed (average $7 \%, 7 \%$, and $9 \%$ of the total identified phenolic compounds present in each analyzed extract sample, respectively). It is worth noting that meta-coumaric acid was identified in all "cambara" honey samples, making it a possible biomarker. In general, the predominant flavonoids were naringenin and galangin, and chrysin was present in the test honeys at low levels.

The radical scavenging activities of the identified phenolic compounds were also screened to evaluate their possible contribution to the antioxidant capacity of the extracts. Their retention times, UV maxima $(\mathrm{nm})$, and antioxidant activity (expressed as $\mathrm{EC}_{50}$ ) are shown in Table 4.

From Table 4, the most hydroxylated compounds, particularly those in ortho positions, such as gallic acid, showed the highest antioxidant activity $\left(\mathrm{EC}_{50}=1.16 \mu \mathrm{g} \mathrm{mL}^{-1}\right)$, while the least hydroxylated compounds, such as benzoic acid, showed inferior antioxidant activity.

Sample M2, which showed the highest antioxidant activity $\left(\mathrm{EC}_{50}\right.$ $\left.=278.61 \mu \mathrm{g} \mathrm{mL}^{-1}\right)$ contained gallic, syringic, and para-coumaric acids, in concentrations of $0.00156 \mathrm{mg} 100 \mathrm{~g} \mathrm{~g}^{-1}, 0.05558 \mathrm{mg} 100 \mathrm{~g}^{-1}$, and

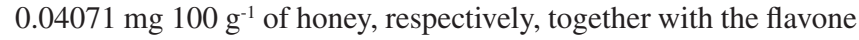

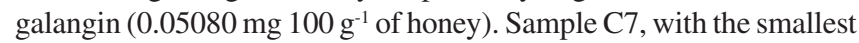
antioxidant capacity $\left(\mathrm{EC}_{50}=1601.89 \mu \mathrm{g} \mathrm{mL} \mathrm{L}^{-1}\right)$, showed mainly the presence of only three phenolic compounds: naringenin $(0.9580 \mathrm{mg}$

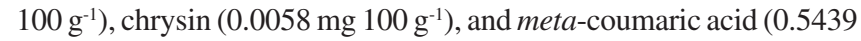
mg $100 \mathrm{~g}^{-1}$ ), which have low antioxidant activity. Benzoic acid was detected at higher levels (average 63\%) in samples C4, C6, C8, and

Table 3. The level of individual compounds quantified in honey extracts (mg $100 \mathrm{~g}^{-1}$ of honey)

\begin{tabular}{|c|c|c|c|c|c|c|c|c|c|c|c|}
\hline & A1 & M2 & A3 & $\mathrm{C4}$ & C5 & C6 & C7 & C8 & C9 & M10 & M11 \\
\hline GA & $0.001 \pm 0.000$ & $0.001 \pm 0.000$ & $0.013 \pm 0.000$ & & $0.027 \pm 0.000$ & $0.121 \pm 0.000$ & $0.060 \pm 0.040$ & & $0.026 \pm 0.000$ & $0.002 \pm 0.001$ & $0.028 \pm 0.007$ \\
\hline $\mathrm{HMF}$ & $0.021 \pm 0.000$ & $0.013 \pm 0.000$ & $0.246 \pm 0.036$ & $0.048 \pm 0.035$ & $0.382 \pm 0.000$ & $0.273 \pm 0.000$ & $0.662 \pm 0.000$ & $0.283 \pm 0.307$ & $0.422 \pm 0.000$ & $0.030 \pm 0.034$ & $0.867 \pm 1.015$ \\
\hline PA & $0.031 \pm 0.014$ & & $0.080 \pm 0.037$ & & & & & & & & \\
\hline 4-HBA & & $0.010 \pm 0.002$ & & & & & & & & $0.005 \pm 0.002$ & $0.165 \pm 0.089$ \\
\hline SA & & $0.055 \pm 0.068$ & & & & & & & $0.371 \pm 0.214$ & & \\
\hline FA & $0.078 \pm 0.029$ & & & & & & & & & & \\
\hline$p-\mathrm{CA}$ & $0.076 \pm 0.050$ & $0.040 \pm 0.041$ & $0.427 \pm 0.036$ & & & & & & & & \\
\hline$m$-CA & & $0.045 \pm 0.061$ & & $0.320 \pm 0.204$ & $0.344 \pm 0.182$ & $1.781 \pm 0.533$ & $0.543 \pm 0.726$ & $0.237 \pm 0.229$ & $0.161 \pm 0.135$ & & \\
\hline BA & $0.026 \pm 0.002$ & $0.104 \pm 0.000$ & & $2.486 \pm 0.019$ & & $14.09 \pm 0.000$ & & $11.23 \pm 0.010$ & $2.473 \pm 0.010$ & & $0.346 \pm 0.031$ \\
\hline$p$-MBA & $0.010 \pm 0.000$ & & $0.163 \pm 0.135$ & & & & & & & & \\
\hline $\mathrm{CA}$ & $0.018 \pm 0.011$ & & $0.039 \pm 0.000$ & & & & & & $0.087 \pm 0.103$ & & \\
\hline $\mathrm{N}$ & & $0.046 \pm 0.034$ & $0.148 \pm 0.000$ & $0.343 \pm 0.072$ & & $1.858 \pm 2.626$ & $0.958 \pm 0.000$ & $0.375 \pm 0.447$ & $0.635 \pm 0.754$ & $0.001 \pm 0.000$ & $0.293 \pm 0.404$ \\
\hline $\mathrm{ABA}$ & $0.045 \pm 0.046$ & $0.067 \pm 0.000$ & $0.394 \pm 0.123$ & $0.062 \pm 0.000$ & $0.175 \pm 0.000$ & $0.657 \pm 0.000$ & $0.328 \pm 0.000$ & $0.021 \pm 0.001$ & $0.155 \pm 0.081$ & $0.016 \pm 0.022$ & $0.264 \pm 0.145$ \\
\hline$m-\mathrm{MCA}$ & & & & $0.347 \pm 0.231$ & $0.718 \pm 0.003$ & $1.138 \pm 0.000$ & & $0.631 \pm 0.752$ & $0.377 \pm 0.000$ & & \\
\hline $\mathrm{CH}$ & $0.001 \pm 0.000$ & & $0.005 \pm 0.000$ & & $0.138 \pm 0.179$ & & $0.005 \pm 0.007$ & $0.253 \pm 0.000$ & $1.370 \pm 0.000$ & & \\
\hline $\mathrm{G}$ & & $0.051 \pm 0.000$ & & & $0.410 \pm 0.000$ & $2.066 \pm 0.000$ & $0.368 \pm 0.007$ & $0.096 \pm 0.000$ & $0.070 \pm 0.063$ & $0.012 \pm 0.000$ & \\
\hline
\end{tabular}

GA- gallic acid; HMF- hydroxymethylfurfural; PA- protocatechuic acid; 4-HBA - 4-hydroxybenzoic acid; SA- syringic acid; FA - ferulic acid; $p$-CA - paracoumaric acid; m-CA - meta-coumaric acid; BA- benzoic acid; $p$-MBA- para-methoxybenzoic acid; CA- cinnamic acid; $m$-MCA - meta-methoxycinnamic acid; N-naringenin; ABA - \pm abscisic acid;. $\mathrm{CH}$ - chrysin; $\mathrm{G}$ - galangin. 
Table 4. Phenolic compounds, retention times $\left(\mathrm{t}_{\mathrm{R}}\right)$, UV maxima $\left(\lambda_{\max }\right)$ and antioxidant activity

\begin{tabular}{lccc}
\hline Phenolic compounds & $\begin{array}{c}\mathrm{t}_{\mathrm{R}} \\
(\mathrm{min})\end{array}$ & $\begin{array}{c}\mathrm{UV}_{\max } \\
(\mathrm{nm})\end{array}$ & $\begin{array}{c}\mathrm{EC}_{50} \\
\left(\mu \mathrm{g} \mathrm{mL}^{-1}\right)^{*}\end{array}$ \\
\hline gallic acid & 3.39 & 270 & $1.16 \pm 0.04$ \\
HMF & 3.77 & 283 & $>5000$ \\
protocatechuic acid & 4.25 & $259 ; 294$ & $2.30 \pm 0.84$ \\
4-hydroxybenzoic acid & 5.82 & 254 & $207.29 \pm 25.81$ \\
syringic acid & 6.32 & 274 & $2.42 \pm 0.27$ \\
ferulic acid & 9.43 & $239 ; 323$ & $4.79 \pm 0.25$ \\
para-coumaric acid & 8.69 & 309 & $39.31 \pm 2.78$ \\
meta-coumaric acid & 11.02 & 278 & $>15000$ \\
benzoic acid & 13.58 & 274 & $>15000$ \\
para-methoxybenzoic acid & 15.03 & 255 & $242.74 \pm 118.55$ \\
cinnamic acid & 21.08 & 276 & $>5000$ \\
naringenin & 21,72 & 289 & $>5000$ \\
ABA & 19.03 & 262 & $>1000$ \\
meta-methoxycinnamic acid & 21.44 & $249 ; 308$ & $>11000$ \\
chrysin & 27.39 & $267 ; 314$ & $>5000$ \\
galangin & 27.77 & $264 ; 360$ & $91.19 \pm 25.05$ \\
\hline
\end{tabular}

*All data expressed on a basis as means $\pm \mathrm{SD}(\mathrm{n}=3)$.

C9. These samples contained large amounts of benzoic acid $(2.49 \mathrm{mg}$ $100 \mathrm{~g}^{-1}, 14.10 \mathrm{mg} 100 \mathrm{~g} \mathrm{~g}^{-1}, 11.24 \mathrm{mg} 100 \mathrm{~g} \mathrm{~g}^{-1}$, and $6.47 \mathrm{mg} 100 \mathrm{~g}^{-1}$ of honey, respectively), a substance that shows hardly any antioxidant capacity $\left(\mathrm{EC}_{50}=15000 \mathrm{mg} \mathrm{mL}^{-1}\right)$, which seems to corroborate the low antioxidant potential of these extracts.

It has been reported that phenolic compounds are the main components responsible for the antioxidant effects of honey, though some other compounds may also be involved. This could explain the changes in antioxidant activity when comparing different honeys and their extracts. ${ }^{13}$

It is interesting to note that compared to the HPLC method, spectrophotometry tends to report higher levels of phenolics. This could be caused by the fact that the nonphenolic materials present in the extracts may interfere with spectrophotometric analysis. ${ }^{4}$

\section{Chemometrics}

Many studies have been conducted to seek for alternatives to sensorial and melissopalynological honey typification. ${ }^{17}$ Analytical methods have been combined with chemometrics. Multivariate analysis using common tests (FRAP, ABTS, DPPH, color, $\mathrm{pH}$, and flavonoid content) has been found to be an efficient method for differentiation of eucalyptus, "morrão de candeia," and "cambara" honeys. ${ }^{7}$

The most widely used variable-reduction method is principal component analysis (PCA). The main goal of PCA is to find relationships between different parameters (samples and variables) and to explore and discriminate complex data.

To evaluate the differences between honeys with different floral origins, a multivariate analysis (PCA) was performed (Figure 1), in which PC1 described $36 \%$ of the variance and PC2 described $25 \%$ of the total variability. PCA score plot presents the positions of the samples in the space of the principal components. PCA performed on HPLC data obtained visible separation of the samples according to their floral origin: "morrão de candeia" was separated from "cambara" and "assa peixe" honeys.

The loadings graph (Figure 1) shows the contributions of the original variables to the PCs and indicates each identified compound (variable) with the highest and lowest influences on floral discrimination. The graph suggests that chrysin, protocatechuic acid, cinnamic acid, para-coumaric acid, gallic acid, 4-hydroxybenzoic acid, meta-methoxycinnamic acid, meta-coumaric acid, and abscisic acid dominate the first component, exhibiting higher distances from the plot origin. The loadings plot indicates that meta-coumaric acid along with meta-methoxycinnamic acid, galangin, and benzoic acid dominate the first component for separation of "cambara" honeys. The concentrations of these polyphenols in "cambara" honeys (mainly meta-coumaric and benzoic acids) show higher differences compared to other honeys (Table 3) and characterizes the different locations of floral origin along PC2.

Compared to "cambara" honeys, 4-hydroxybenzoic acid and ABA dominate the separation between the two different origins, whereas differences in chrysin, protocatechuic acid, cinnamic acid, para-coumaric acid, and gallic acid characterize the position of "assa peixe" honeys in the PCA scores plot. Thus, both meta-coumaric acid and meta-methoxycinnamic acid are potential biomarkers for "cambara" honeys, as well as 4-hydroxybenzoic acid for "morrão de candeia" honeys. These compounds can be found in their respective samples and were also influential variables in honey discrimination.

Honey metabolomics based on the phenolic profile is usually performed using ${ }^{1} \mathrm{HNMR}$ data. ${ }^{18}$ In general, discrimination of honey samples from different botanical flora is satisfactory and used to authenticate samples. HPLC is a good alternative when compared to ${ }^{1} \mathrm{HNMR}$. It can be argued that the first method is advantageous over the second in terms of simplicity of identification and data
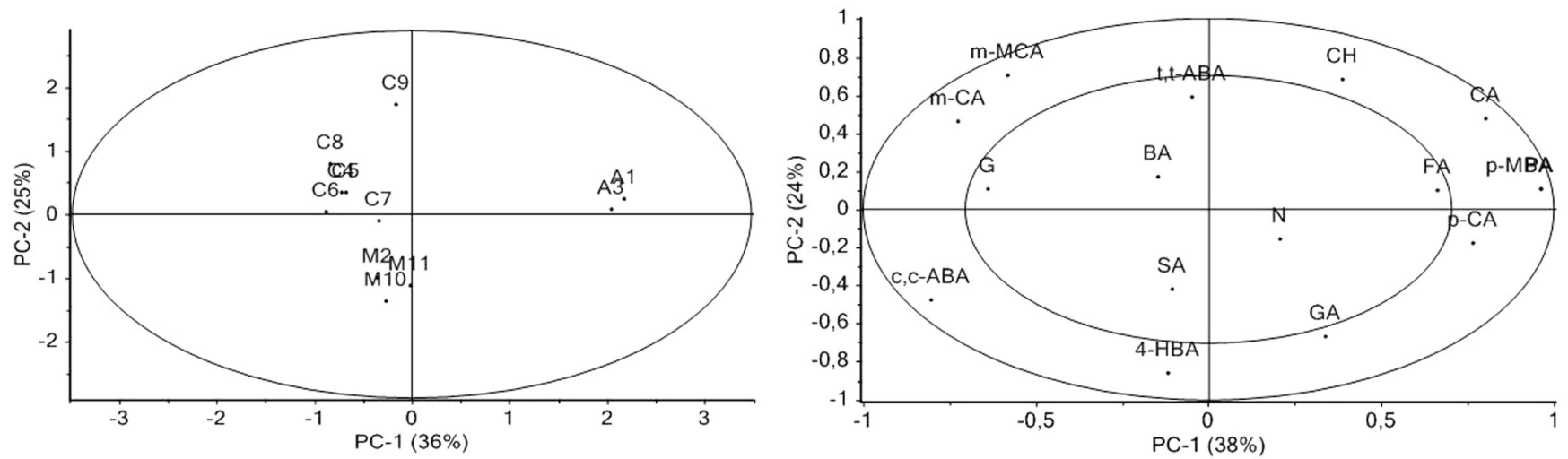

Figure 1. Principal component analysis (left) and loadings graph (right): GA - gallic acid, PA - protocatechuic acid, 4-HBA - 4-hydroxybenzoic acid, p-CA para-coumaric acid, m-CA - meta-coumaric acid, CA - cinnamic acid, m-MCA - meta-methoxycinnamic acid, ABA - abscisic acid, and CH - chrysin 
quantification because of the use of standards for comparison of the peaks in the chromatogram.

\section{CONCLUSIONS}

The results indicate that of the three Brazilian honey types analyzed, "cambara" honey exhibited the highest content of phenolics and flavonoids, and also the highest antioxidant capacity. The antioxidant activity of the honey extracts studied in this work may be related to the antioxidant abilities of the phenolic acids and flavonoids that were identified. Analysis of the honey extracts by HPLC resulted in the identification of gallic, protocatechuic, 4-hydroxybenzoic, syringic, ferrulic, para-coumaric, meta-coumaric, benzoic, para-methoxybenzoic, cinnamic, and meta-methoxycinnamic acids and three flavonoids (naringenin, chrysin, and galangin) in all the samples tested. This study confirms that the profile of phenolic acids and flavonoids is affected by the floral origin of honeys to the point of contributing to their botanical and geographical differentiation.

Preliminary measurements of phenolic compounds in honey extracts clearly demonstrate that a relationship exists between the concentration of individual phenolic compounds and antioxidant properties.

PCA analysis appears to be a useful tool for differentiation of honey authenticity (in the sense of botanical origin of samples) using the phenolic compounds profile. The results obtained using PCA confirm that data on phenolic compounds data are suitable for differentiation of honey samples according to their type, making it possible to separate the samples into three groups. Thus, 4-hydroxybenzoic acid for "morrão de candeia" honeys and both meta-coumaric acid and meta-methoxycinnamic acid are suggested as potential biomarkers for "cambara" honeys.

\section{SUPPLEMENTARY MATERIAL}

Available at http://quimicanova.sbq.org.br in PDF format with free access.

\section{ACKNOWLEDGMENTS}

The authors acknowledge financial support and fellowships from CNPq, FAPERJ, and CAPES.

\section{REFERENCES}

1. Khalil, M. I.; Sulaiman, S. A.; Boukraa, L.; Open Nutraceuticals J. 2010, 3, 6 .

2. White, J. W.; Composition of honey. Honey. A comprehensive survey, Crane, Russak \& Company: London, 1975.

3. Alvarez-Suarez, J. M.; Gonzalez-Paramas, A. M.; Santos-Buelga, C.; Battino, M.; J. Agric. Food Chem. 2010, 58, 9817; Gheldof, N.; XiaoHong, W.; Engeseth, N.; J. Agric. Food Chem. 2002, 50, 5870.

4. Khalil, M. I.; Alam, N.; Moniruzzaman, M.; Sulaiman, S. A.; Gan, S. H.; J. Food Sci. 2011, 76, 921

5. Lianda, R. L. P.; Castro, R. N.; Quim. Nova 2008, 31, 1472; Pyrzynska, K.; Biesaga, M.; TrAC, Trends Anal. Chem. 2009, 28, 893; Ferreira, I. C. F. R.; Aires, E.; Barreira, J. C. M.; Estevinho, L. M.; Food Chem. 2009, 14, 1438.

6. Singleton, V. L.; Orthofer, R.; Lamuela-Raventos, R. M.; (1999). Methods Enzymol. 1999, 299, 152.

7. Sant'Ana, L. D'O.; Sousa, J. L. M.; Salgueiro, F. B.; Lorenzon, M. C. A.; Castro, R. N.; J. Food Sci. 2012, 71, 135.

8. Zhang, D.; Hamauzu, Y.; Food Chem. 2004, 88, 503.

9. Mensor, L. L.; Menezes, F. S.; Leitão, G. G.; Reis, A. S.; Santos, T. C.; Coube, C. S.; Leitão, S. G.; Phytother. Res. 2001, 15, 127.

10. Sant'Ana, L. D'O.; Buarque Ferreira, A. B.; Lorenzon, M. C. A.; Berbara, R. L. L.; Castro, R. N. Int. J. Food Prop. 2014, 17, 65.

11. Lianda, R. L. P.; Sant'Ana, L. D’O.; Echevarria, A.; Castro, R. N.; J. Braz. Chem. Soc. 2012, 23, 618.

12. Silva, A. A. I.; Silva, S. M. T.; Camara, A. C.; Queiroz, N.; Magnani, M.; de Novais, S. J.; Soledade, B. E. L.; Lima, O. E.; Souza, L. A.; Souza, G. A. Food Chem. 2013, 141, 3552.

13. Gheldof, N.; Engeseth, N. J.; J. Agric. Food Chem. 2002, 50, 3050; Erejuwa, O. O.; Sulaiman, S. A.; Wahab, M. S. A.; Molecules 2012, 17, 4400.

14. Benzie, I. F.; Strain, J.; Anal. Biochem. 1996, 239, 70; Re, R.; Pellegrini, N.; Proteggente, A.; Pannala, A.; Yang, M.; Rice-Evans, C.; Free Radical Biol. Med. 1999, 26, 1231.

15. Estevinho, L.; Pereira, P. A.; Moreira, L.; Dias, G. L.; Pereira, E.; Food Chem. Toxicol. 2008, 46, 3774.

16. Jasicka-Misiak, I.; Poliwoda, A.; Deren, M.; Kafarski, P.; Food Chem. 2012, 131, 1149.

17. Bertoncelj, J.; Golob, T.; Kropf, U.; Korosec, M.; Food Sci. Technol. 2011, 46, 1661.

18. Boffo, E. F.; Tavares, L. A.; Tobias, A. C. T.; Ferreira, M. M. C.; Ferreira, A. G.; Food Sci. Technol. 2012, 49, 55. 